International Journal of Automotive and Mechanical Engineering (IJAME)

ISSN: 2229-8649 (Print); ISSN: 2180-1606 (Online); Volume 7, pp. 1023-1030, January-June 2013

(C) Universiti Malaysia Pahang

DOI: http://dx.doi.org/10.15282/ijame.7.2012.18.0083

\title{
FINITE ELEMENT MODELING OF DELAMINATION PROCESS ON COMPOSITE LAMINATE USING COHESIVE ELEMENTS
}

\author{
S. Huzni ${ }^{1 *}$, Ilfan M. ${ }^{1}$, Sulaiman T. ${ }^{1}$, S. Fonna ${ }^{1,2}$, M.Ridha ${ }^{1}$ and A.K. Arifin ${ }^{2}$ \\ ${ }^{1}$ Department of Mechanical Engineering, Syiah Kuala University \\ Jl. Tgk. Syech Abdurrauf No. 7 Darusalam - Banda Aceh 23111, Indonesia \\ Phone/Fax.: +62-651-7428069 \\ *E-mail: syifaul@unsyiah.ac.id \\ ${ }^{2}$ Department of Mechanical \& Materials Engineering, \\ Faculty of Engineering \& Built Environment \\ National University of Malaysia, Bangi, Selangor, Malaysia.
}

\begin{abstract}
The implementation of cohesive elements for studying the delamination process in composite laminates is presented in this paper. The commercially available finite element software ABAQUS provides the cohesive element model used in this study. Cohesive elements with traction-separation laws consist of an initial linear elastic phase, followed by a linear softening that simulates the debonding of the interface after damage initiation is inserted at the interfaces between the laminas. Simulation results from two types of composite laminate specimen, i.e., a double cantilever beam and an L-shape, show that the delamination process on laminated composites begin with debonding phenomena. These results indicate that the implementation of cohesive elements in modeling the process of delamination in laminated composite materials, using the finite element method, has been successful. Cohesive elements are able to model the phenomenon of delamination in the specimens used in this study.
\end{abstract}

Keywords: Cohesive element; composite laminate; delamination; finite element method.

\section{INTRODUCTION}

Laminated composites are one of the materials widely used for replacing metals in many engineering structures, such as spacecraft, aircraft, ship hulls, and sports equipment owing to their high specific stiffness, high strength, and low weight (Gürdal et al., 1999). Even though widely utilized, the potential and behavior of laminated composites are not fully exploited (Ibrahim et al., 2012; Dechaene et al., 2002; Jeffrey et al., 2011; Adebisi et al., 2011). Thus, further investigation is required, especially related to failure mechanisms of composite laminates. Delamination is one of the most common failure modes that may occur between laminas subjected to transverse loading. Delamination occurs when the bonds between layers of the laminate fail due to debonding in the plane of the interface adhesion (Remmers and de Borst, 2001). The existence of delaminations can reduce the strength, stiffness, and load-bearing capacity of the laminate under compressive loads (Shan, 2007). Extensive research has been carried out on the delamination mechanism of composite laminates (Umar et al., 2012; Saponara et al., 2002; Zou et al., 2002; Bachtiar et al., 2010; Bhaskar and Sharief, 2012; Elmarakbi et al., 2009; Wimmer et al., 2009; Hardinnawirda and SitiRabiatull 
Aisha, 2012; Gözlüklü and Coker, 2012; Pajand et al., 2012). Detecting this type of damage is still a serious problem in composite structures.

Numerical tools such as ABAQUS, which is based on the finite element method, have been widely used to study the delamination mechanism of composite laminates (Liu, 2012). ABAQUS provides a special element called the cohesive element that can be used to model crack initiation and propagation in laminated composite structures. A main advantage of the use of cohesive elements is the capability to predict both the onset and propagation of delamination without previous knowledge of the initial crack location (Temesgen and Anastasios, 2010). In this paper, the implementation of cohesive elements for studying the delamination process in laminated composites is presented. The delamination mechanism of two types of specimen, i.e., a double cantilever beam and an L-shape are discussed. The ability of cohesive elements, provided by the ABAQUS software, will be useful for further investigation on the delamination mechanisms of composite laminates.

\section{METHODS AND MATERIALS}

\section{Model geometry}

Two types of specimen geometry are used is this study: a double cantilever beam (DCB), and an L-shape. Both specimen geometries were created using pre-processing facilities provided by the ABAQUS 6.10-1 software.

\section{Double Cantilever Beam}

The DCB is one of the most common specimens used to evaluate mode I interlaminar fracture in a composite laminate. The specimen is created by inserting an adhesive layer between two laminas. The size and geometry of each layer can be seen from Figure 1. The properties of the material used for the DCB specimen, adopted from Morais et al. (2000), can be seen in Table 1. The material properties were chosen in order to facilitate the implementation of a cohesive element for studying the mechanisms of delamination in composite laminates, not to examine the properties of certain materials under certain loading conditions. The binder layer, which is represented by the cohesive element in the finite element analysis, has the properties shown in Table 2. A traction-separation law, which consists of an initial linear elastic phase, followed by a linear softening that simulates the debonding of the interface after damage initiation, is utilized in the finite element cohesive model. Continuum shell elements with a size of $2.5 \times 10^{-3} \mathrm{~m}$ were employed for the top layer and bottom layer, which is the representation of the laminas. The cohesive element with a size of $1.25 \times 10^{-3} \mathrm{~m}$ is employed in the cohesive layer.

Table 1. Properties of lamina (Morais et al., 2000).

\begin{tabular}{cccccc}
\hline $\mathrm{E}_{11}$ & $\mathrm{E}_{22}=\mathrm{E}_{33}$ & $v_{12}=v_{13}$ & $v_{23}$ & $\mathrm{G}_{12}=\mathrm{G}_{13}$ & $\mathrm{G}_{23}$ \\
\hline $150 \mathrm{GPa}$ & $11 \mathrm{GPa}$ & 0.25 & 0.45 & $6 \mathrm{GPa}$ & $3.7 \mathrm{GPa}$ \\
\hline
\end{tabular}


Table 2. Properties of the cohesive element (Dávila et al., 2001).

\begin{tabular}{cccc}
\hline \multicolumn{3}{c}{ Double Cantilever Beam } & \multicolumn{2}{c}{ L-shape } \\
\hline $\mathrm{K}_{\mathrm{n}}=1.1 \times 10^{15} \mathrm{~N} / \mathrm{m}^{3}$ & $\mathrm{~K}_{\mathrm{n}}=2.2 \times 10^{14} \mathrm{~N} / \mathrm{m}^{3}$ & $\mathrm{~N}_{\max }=30 \mathrm{MPa}$ & $\mathrm{N}_{\max }=30 \mathrm{Mpa}$ \\
$\mathrm{K}_{\mathrm{s}}=1.2 \times 10^{15} \mathrm{~N} / \mathrm{m}^{3}$ & $\mathrm{~K}_{\mathrm{s}}=2.4 \times 10^{14} \mathrm{~N} / \mathrm{m}^{3}$ & $\mathrm{~S}_{\max }=40 \mathrm{MPa}$ & $\mathrm{S}_{\max }=40 \mathrm{Mpa}$ \\
$\mathrm{K}_{\mathrm{t}}=0.74 \times 10^{15} \mathrm{~N} / \mathrm{m}^{3}$ & $\mathrm{~K}_{\mathrm{t}}=1.48 \times 10^{14} \mathrm{~N} / \mathrm{m}^{3}$ & $\mathrm{~T}_{\max }=40 \mathrm{MPa}$ & $\mathrm{T}_{\max }=40 \mathrm{MPa}$ \\
\multicolumn{2}{c}{$\mathrm{G}_{\mathrm{Ic}}=268 \mathrm{~J} / \mathrm{m}^{2}$} & & \\
\hline
\end{tabular}

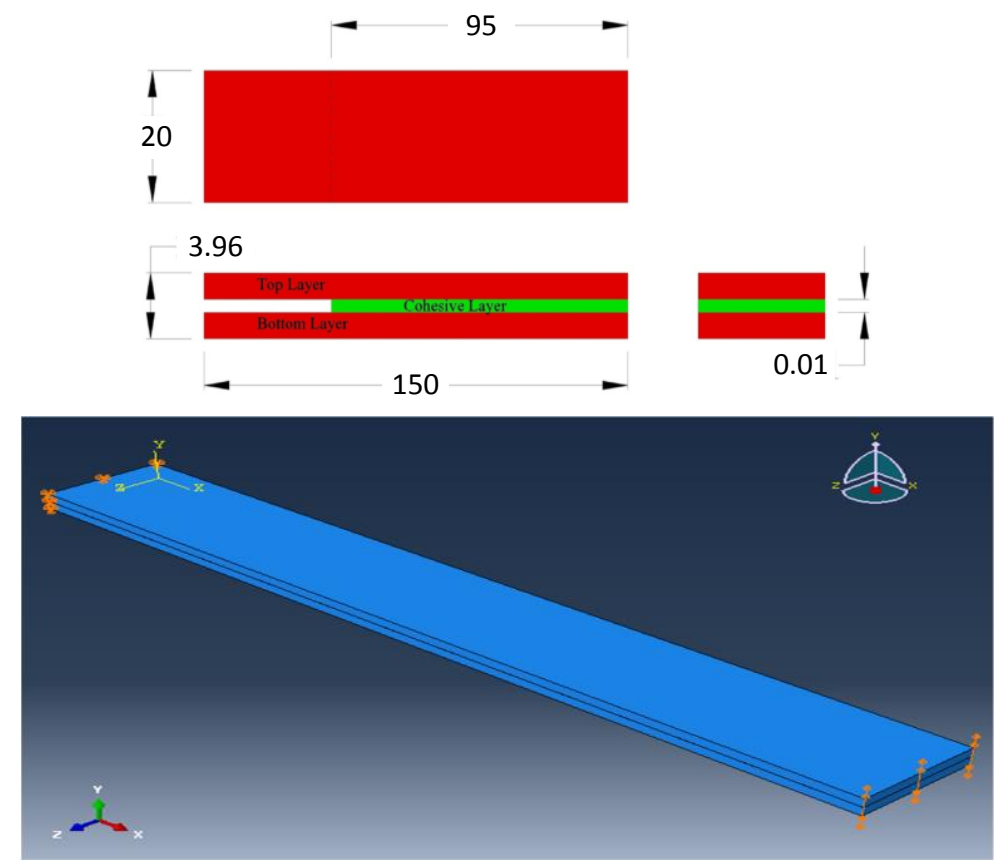

Figure 1 . Geometry and size of DCB specimen.

\section{L-shape}

This type of specimen is widely used to model complex shapes of a composite laminate structure. The sharp curved geometry of an L-shaped beam produces interlaminar opening stresses, which in turn lead to delamination under mixed loading conditions. In this study, nine layers were arranged to form an L-shaped composite laminate in the formation of lamina+binder+lamina+binder and so on, as shown in Figure 2. The material properties of the L-shaped laminas and cohesive elements used in this work can be seen in Tables 1 and 2 .

\section{RESULTS AND DISCUSSION}

\section{Double Cantilever Beam}

The openings phenomenon that occurs in the DCB specimen due to mode I loading can be seen in Figure 3. Both layers (top and bottom) part from each other and produce the crack mouth. A more detailed observation of the displacement contours of a cohesive layer indicates that the cracks initiated at the end of the cohesive layer, which is the crack tip. 

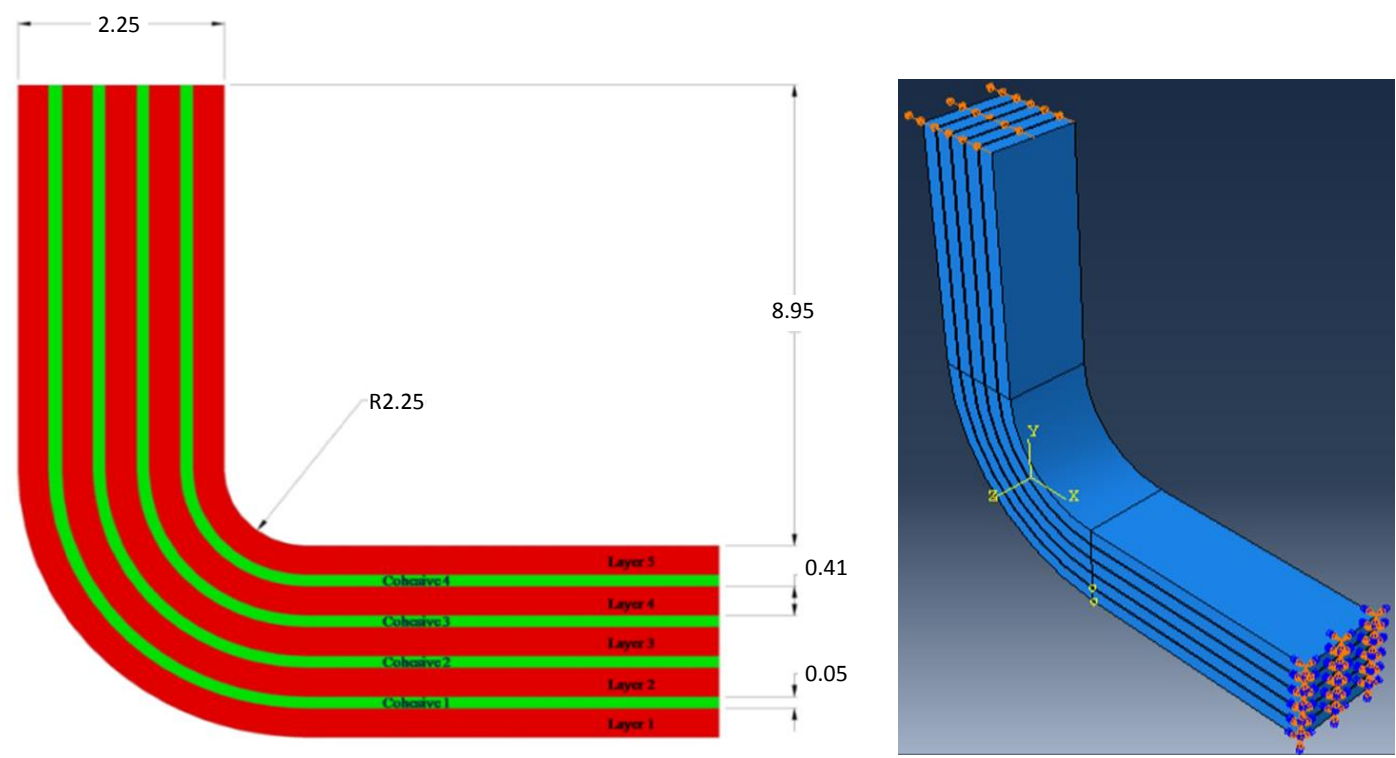

Figure 2. L-shape size, geometry and boundary condition.

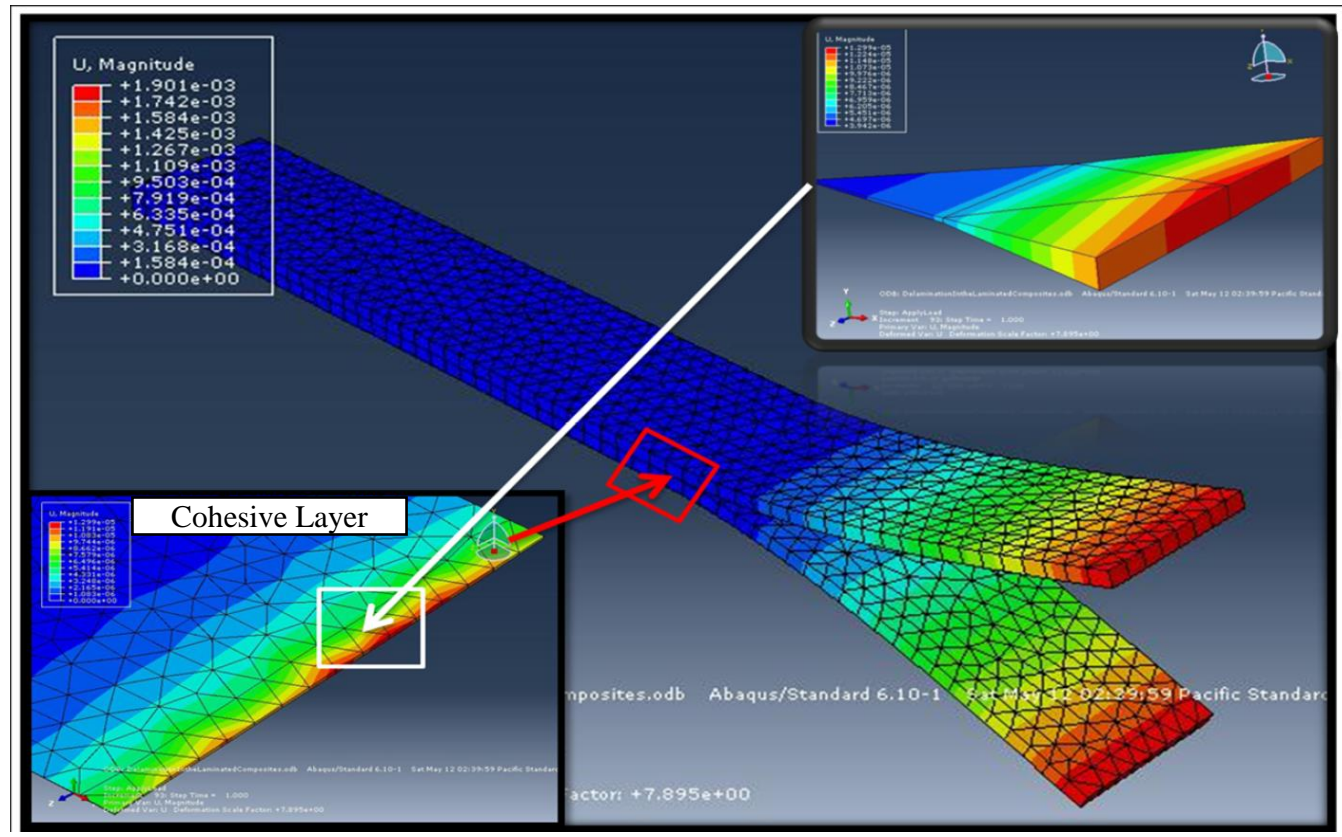

Figure 3. Displacement of double cantilever beam.

The evolution of the composite laminate delamination process of the DCB specimen can be seen through the load-displacement curve shown in Figure 4. The delamination process initiates at the crack tip of the DCB specimen. If the crack initiation continues as the load increases, the bond between the laminas with a cohesive layer will break. One of the criteria that could be used to predict the initiation of delamination in composite laminates is the quadratic failure criterion. This criterion states that delamination will occur if the quadratic failure criterion value is equal to 1 . 


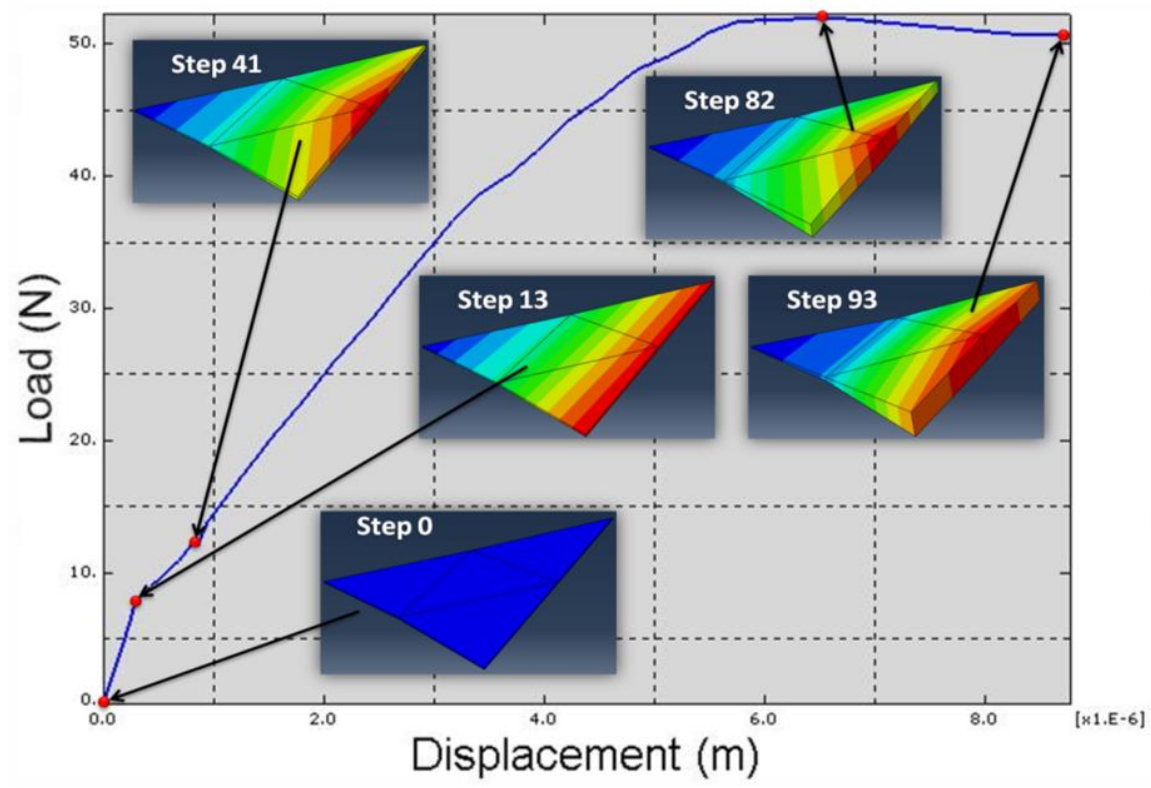

Figure 4. Load-displacement curve of DCB specimen.

The cohesive element model used in this simulation is shown to function properly. When the delamination process occurs continuously, the crack continues to propagate, as can be seen in Figure 5. The displacement contour in Figure 5 shows that the crack initiation occurs in some parts in the middle of the specimen. When the load is increased, then it is likely that the crack propagates at different speeds from one location to another in the field of the crack propagation.

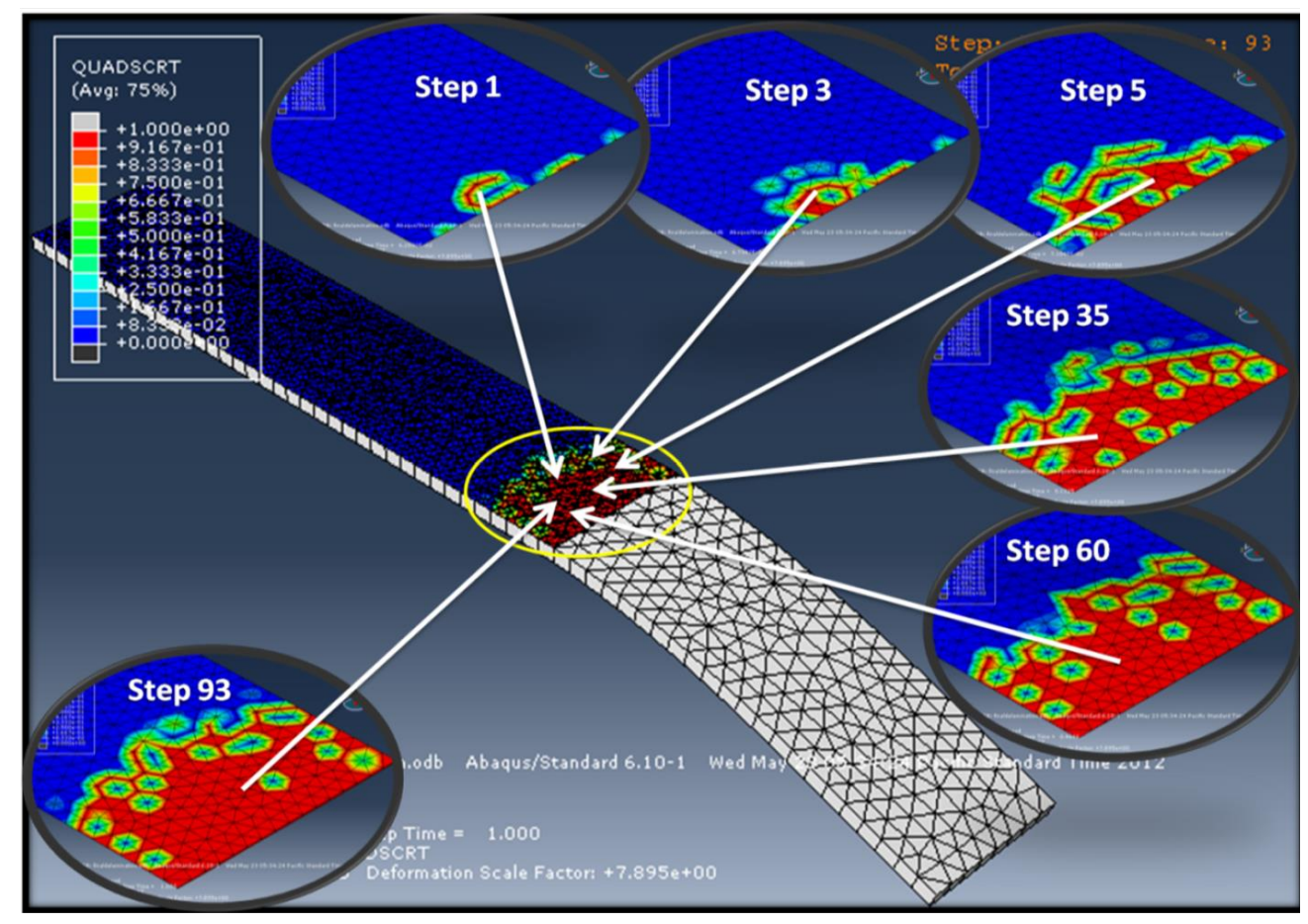

Figure 5. Crack propagation process on cohesive layer. 


\section{L-shape}

The stress distribution contour of the L-shaped specimen can be seen in Figure 6. This specimen comprises five layers of lamina and four layers of cohesive element arranged alternately to form the composite laminate structure. By applying the load in the direction perpendicular to the arm, as shown in Figure 2, mixed mode loading conditions occurs in the corner area of the L-shape. The combination of mode I and mode II leads to the initiation of delamination around the corner of the specimen, which will eventually cause cracking.

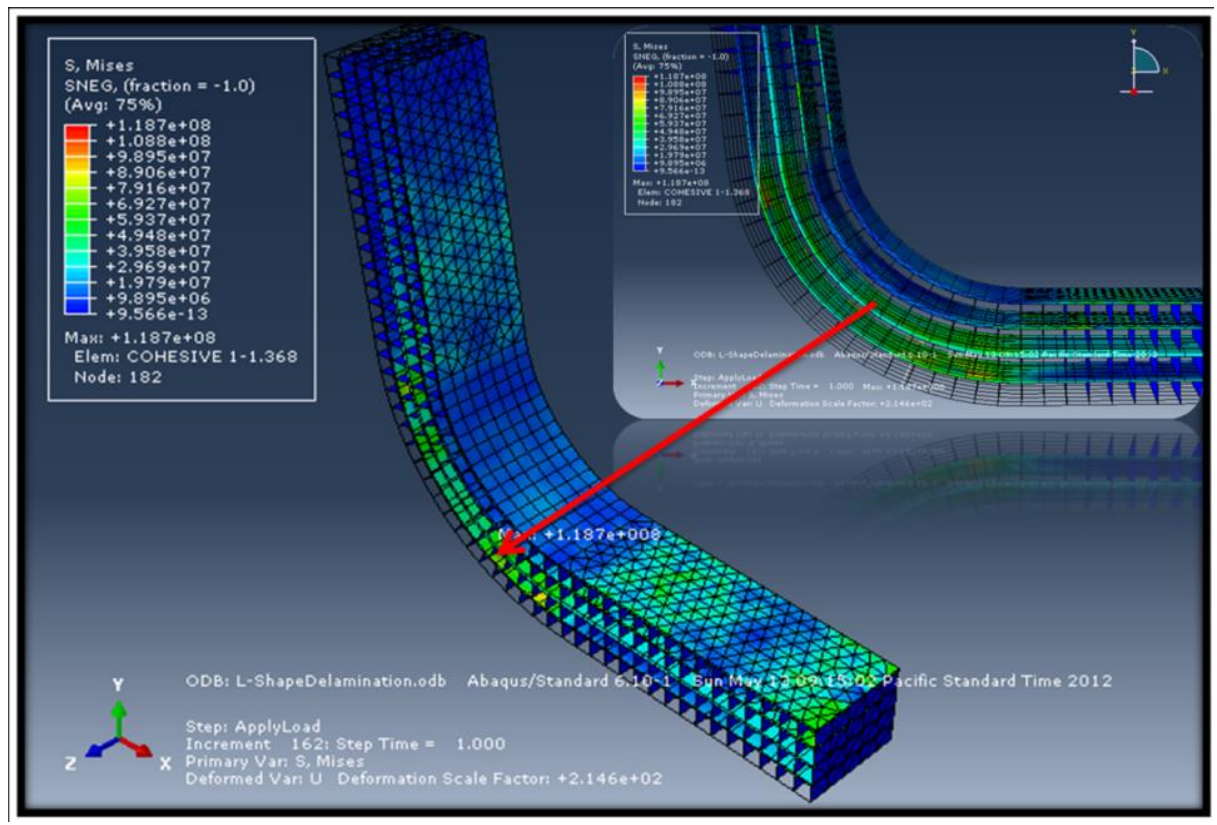

Figure 6. Stress distribution contour on L-shaped specimen.

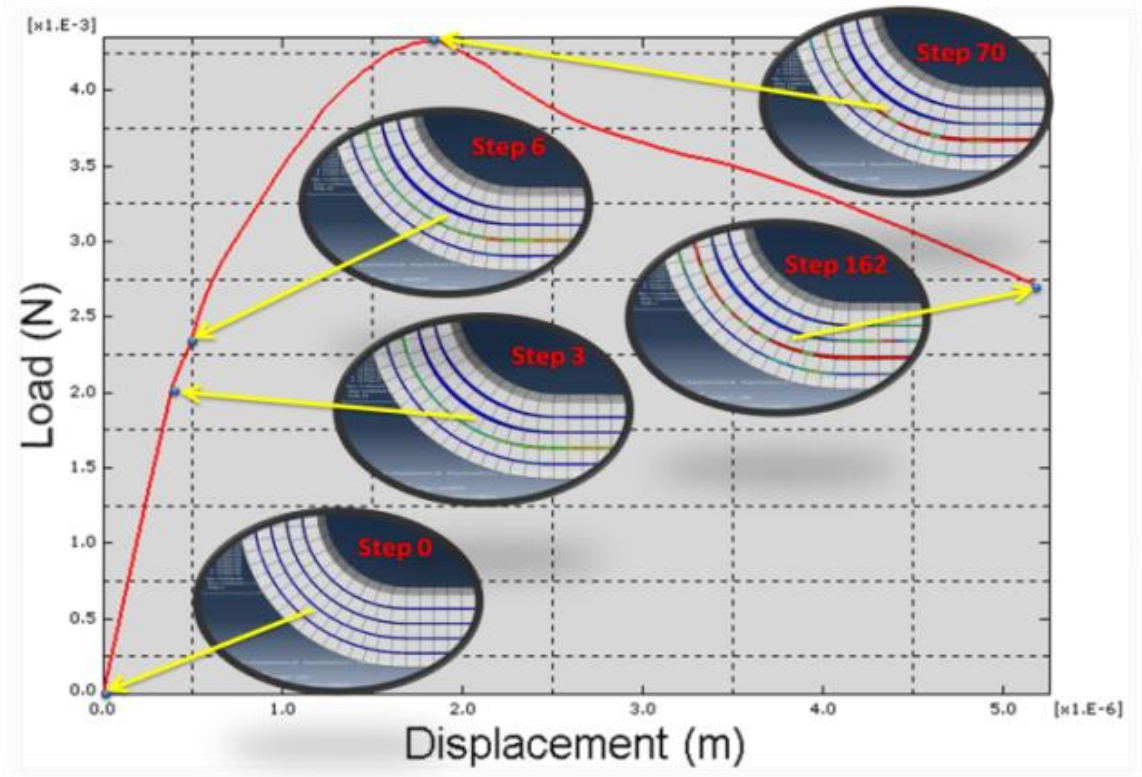

Figure 7. Load-displacement curve. 
The evolution of the composite laminate delamination process of the L-shaped specimen can be seen through the load-displacement curve shown in Figure 7. The delamination process initiates in the curvature area of the L-shaped specimen. If the crack initiation continues as the load increases, the bond between the laminas with a cohesive layer will break. These results are consistent with the results of research conducted by Wimmer et al. (2006), who used the Puck delamination criteria, which also showed that the delamination process initiates in the curvature area of the L-shaped specimen.

\section{CONCLUSIONS}

Modeling of delamination mechanisms in laminated composite materials using cohesive elements in the commercially available ABAQUS software has been successfully implemented. Cohesive elements with a traction-separation law have been used successfully to simulate the process of delamination initiation and crack propagation in double cantilever beam and L-shaped specimens. Simulation results on both specimens show that the delamination process begins with the debonding phenomenon.

\section{ACKNOWLEDGMENTS}

The authors would like to express their gratitude to Laboratorium Rekayasa MaterialJurusan Teknik Mesin UNSYIAH and CCRG (Corrosion and Computational Research Group) for providing laboratory facilities and financial assistance.

\section{REFERENCES}

Adebisi, A.A., Maleque, M.A. and Rahman, M.M. 2011. Metal matrix composite brake rotor: historical development and product life cycle analysis. International Journal of Automotive and Mechanical Engineering, 4: 471-480.

Aure, T.W. and Ioannides, A.M. 2010. Simulation of crack propagation in concrete beams with cohesive elements in ABAQUS. Transportation Research Record: Journal of the Transportation Research Board, 21540: 12-21.

Bachtiar, D., Sapuan, S.M. and Hamdan, M.M. 2010. Flexural properties of alkaline treated sugar palm fibre reinforced epoxy composites. International Journal of Automotive and Mechanical Engineering, 1: 79-90.

Bhaskar, H.B. and Sharief,A. 2012. Effect of solutionizing on dry sliding wear of A12024-Beryl metal matrix composite. Journal of Mechanical Engineering and Sciences, 3: 281-290.

Dávila, C.G., Camanho, P.P. and de Moura, M.F. 2001. Mixed-mode decohesion elements for analyses of progressive delamination. $42^{\text {nd }}$ AIAA/ASME/ASCE/ AHS/ASC Structures, Structural Dynamics and Materials Conference.

Dechaene, R., Degrieck, J., Lannucci, L. and Willows, M. 2002. A constitutive model for glass fibre fabric composites under impact. Journal of Composite Materials, 36: 983-1004.

Elmarakbi, A.M., Hub, N. and Fukunaga, H. 2009. Finite element simulation of delamination growth in composite materials using LS-DYNA. Composites Science and Technology, 69: 2383-2391.

Gözlüklü, B. and Coker, D. 2012. Modeling of the dynamic delamination of L-shaped unidirectional laminated composites. Composite Structures, 94: 1430-1442. 
Gürdal, Z., Haftka, R.T. and Hajela, P. 1999. Design and optimization of laminated composite materials. Canada: John Wiley \& Sons.

Hardinnawirda, K. and SitiRabiatull Aisha, I. 2012. Effect of rice husks as filler in polymer matrix composites. Journal of Mechanical Engineering and Sciences, 2: 181-186.

Ibrahim, M.S., Sapuan, S.M. and Faieza, A.A. 2012. Mechanical and thermal properties of composites from unsaturated polyester filled with oil palm ash. Journal of Mechanical Engineering and Sciences, 2: 133-147.

Jeffrey, K.J.T., Tarlochan, F. and Rahman, M.M. 2011. Residual strength of chop strand mats glass fiber/epoxy composite structures: effect of temperature and water absorption. International Journal of Automotive and Mechanical Engineering, 4: 504-519.

Liu, H.Q. 2012. Ply Clustering Effect On Composite Laminates Under Low-Velocity Impact Using Fea. Master Thesis. School of Engineering, MSc Aircrft Design Programme, Cranfield University, UK.

Morais, A.B., Marques, A.T. and de Castro, P.T. 2000. Estudo da aplicação de ensaios de fractura interlaminar de modo i a laminados compósitos multidireccionais. Proceedings of the 7 as Jornadas De Fractura, Sociedade Portuguesa de Materiais Portugal, pp. 90-95.

Remmers, J.J.C. and de Borst, R. 2001. Delamination buckling of fibre-metal laminates. Composites Science and Technology, 61: 2207-2213.

Rezaiee-Pajand, M., Shahabian, F. and Tavakoli, F.H. 2012. Delamination detection in laminated composite beams using hybrid elements. Composite Structures, 94: 2777-2792.

Saponara, V.L., Muliana, H., Haj-Ali, R. and Kardomateas, G.A. 2002. Experimental and numerical analysis of delamination growth in double cantilever laminated beams. Engineering Fracture Mechanics, 69: 687-699.

Shan, L.Y. 2007. Explicit buckling analysis of fiber-reinforced plastic (FRP) composite structures. Phd Thesis. Department of Civil and Environmental EngineeringWashington State University, USA.

Umar, A.H., Zainudin, E.S. and Sapuan, S.M. 2012. Effect of accelerated weathering on tensile properties of kenaf reinforced high-density polyethylene composites. Journal of Mechanical Engineering and Sciences, 2: 198-205.

Wimmer, G., Schuecker, C. and Pettermann, H.E. 2006. Numerical simulation of delamination onset and growth in laminated composites. The E-Journal of Nondestructive Testing, 11: 12

Wimmer, G., Schuecker, C. and Pettermann, H.E. 2009. Numerical simulation of delamination in laminated composite components - A combination of a strength criterion and fracture mechanics. Composites: Part B, 40: 158-165.

Zou, Z., Reid, S.R., Li, S. and Soden, P.D. 2002. Application of a delamination model to laminated composite structures. Composite Structures, 56: 375-389. 